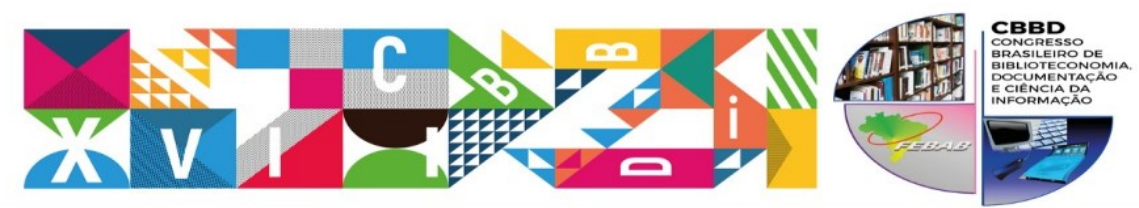

XXVII CONGRESSO BRASILEIRO DE BIBLIOTECONOMIA,

DOCUMENTAÇÃO E CIÊNCIA DA INFORMAÇÃO

TEMA CENTral: Objetivos para o Desenvolvimento Sustentável das Naçōes Unidas:
como as bibliotecas podem contribuir com a implementaçāo da Agenda 2030

Eixo 2 - $3^{\circ}$ Fórum de Biblioteconomia Escolar

\title{
O BIBLIOTECÁRIO ESCOLAR DIANTE DOS NATIVOS DIGITAIS
}

\author{
Raquel Miranda Vilela Paiva \\ Doutoranda em Ciência da Informação \\ pela Universidade Federal de Minas \\ Gerais. \\ E-mail: quelvilela@yahoo.com.br
}

\section{Adriana Bogliolo Sirihal Duarte}

Doutora em Ciência da Informação pela Universidade Federal de Minas Gerais.

E-mail: bogliolo@eci.ufmg.br

\section{RESUMO}

A biblioteca no contexto escolar possui especificidades a que o profissional deve estar atento. Sua atuação deve ir além do tecnicismo biblioteconômico, utilizando-se de elementos pedagógicos e de acordo com as necessidades dos usuários, sendo os mais representativos os alunos da escola. As crianças e jovens que estão atualmente nas escolas podem ser chamados de nativos digitais e possuem uma relação distinta com a informação. 0 presente trabalho visa justamente conhecer a percepção e o imaginário de um bibliotecário escolar sobre os nativos digitais, e isso é feito adotando-se a metodologia de associação de palavras. 0 experimento de associação de palavras é utilizado na psicologia e o trabalho se baseou nas premissas de Carl Jung e na sua forma de aplicação do experimento. A associação de palavras pretende ser um caminho de acesso ao inconsciente do pesquisado. 0 experimento demonstrou que o universo dos nativos digitais ainda é novo e pouco conhecido do bibliotecário, mas nota-se uma preocupação do profissional em sua atuação com esses jovens e crianças. Conclui-se que é necessário o desenvolvimento de mais estudos e a promoção de debates sobre o tema dos nativos digitais e sua inserção na biblioteca escolar.

Palavras-chave: Biblioteca Escolar; Bibliotecário Escolar; Nativos Digitais; Associação de Palavras.

THE SCHOOL LIBRARIAN IN FRONT OF THE

DIGITAL NATIVES

\section{ABSTRACT}

The library in the school context has specificities to which the librarian should be attentive. Its performance should go beyond the technical issues, including pedagogical elements and paying attention 


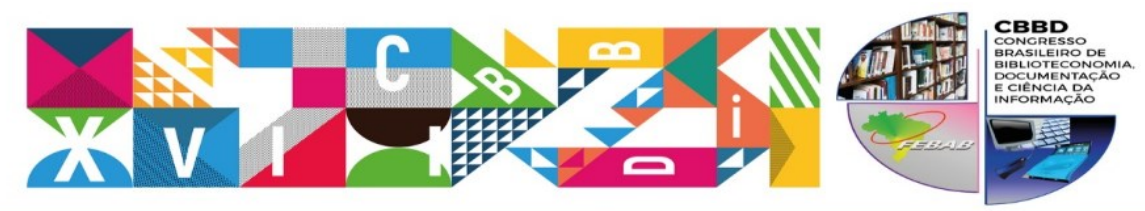

XXVII CONGRESSO BRASILEIRO DE BIBLIOTECONOMIA,

DOCUMENTAÇÃO E CIÊNCIA DA INFORMAÇÃO

TEMA CENIral: Objetivos para o Desenvolvimento Sustentável das Naçōes Unidas:
como as bibliotecas podem contribuir com a implementaçāo da Agenda 2030

to the needs of users who are, mostly, students. Children and young people who are currently in school can be called digital natives and have a distinct relationship with information. The present research aims precisely to know the perception and the imaginary of a school librarian about the digital natives, and this is done adopting the methodology of word association. The word association test is used in psychology and this research was based on the premises of Carl Jung and his application of the test. The word association method is meant to be a way of accessing the subject's unconscious. The experiment demonstrated that the universe of digital natives is still new and little known to the librarian, althoughshe is concernedwith them in her work. It is concluded that it is necessary to expand the investigation by developing more studies and also to promote debates on the topic of digital natives and their insertion in the school libraries.

Keywords: School library; School librarian; Digital natives; Word association.

\section{INTRODUÇÃO}

O presente artigo se dispõe a refletir sobre a forma como o bibliotecário escolar vê os nativos digitais, a nova geração de alunos presentes nas escolas. Para procurar entender o imaginário desses profissionais foi utilizado o experimento de associação de palavras, a fim de acessar o inconsciente do mesmo.

Desde a década de 1970 pode-se encontrar estudos sobre a biblioteca escolar (BE) no Brasil. Esses estudos demonstram a profunda relação entre os conceitos e utilidades desse equipamento com a situação da educação no país. Ainda que nem sempre esteja presente nas escolas, é importante destacar que a Lei no. 12.244 de 2010 (BRASIL, 2010) regulamenta que, no prazo de 10 anos, todas as escolas, sejam públicas ou privadas, deverão ser dotadas de biblioteca. Essa lei traz consigo uma perspectiva de que a BE passe a ser disseminada.

A escola que possui, dentre seus recursos, a biblioteca, deve contar no seu quadro de profissionais com o bibliotecário. Assim, esse profissional deve adequar sua atuação 


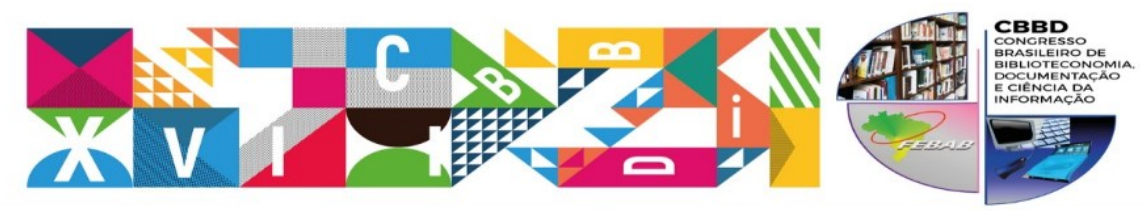

XXVII CONGRESSO BRASILEIRO DE BIBLIOTECONOMIA,

DOCUMENTAÇÃO E CIÊNCIA DA INFORMAÇÃO

TEMA CENIraL: Objetivos para o Desenvolvimento Sustentável das Naçōes Unidas:
como as bibliotecas podem contribuir com a implementaçăo da Agenda 2030

ao contexto escolar, estando disposto a servir como catalisador e mediador da informação, atuando de forma dinâmica e integrada à atuação pedagógica dos docentes. Esse profissional deve dominar não apenas as técnicas biblioteconômicas, mas também ter noções da área de Educação, para realmente atuar como educador.

Soares (2014) sintetiza o panorama da atuação pedagógica do bibliotecário salientando que

podemos dizer que os empecilhos para o exercício do papel pedagógico são principalmente a ênfase nas atividades técnicas e a falta de interação entre bibliotecários e professores. Soma-se a esses o fato de o bibliotecário não possuir formação suficiente para exercer este papel, conforme explicitado por diversos autores (SOARES, 2014, p. 21).

A crítica implícita por Soares refere-se ao fato de que os currículos dos cursos superiores de Biblioteconomia, responsáveis pela formação dos bibliotecários são, em sua maioria, generalistas, pretendendo formar o profissional para atuar em diferentes contextos e ambientes.Portanto, não formam o profissional especialista para atuar especificamente no ambiente escolar. Isso significa que nem sempre os cursos contemplam a formação para que o profissional atue com crianças e jovens, para que seja um mediador da leitura e da informação, para que conheça currículo escolar e projeto político pedagógico das escolas, ou para que tenha habilidades de atuar como instrutor. Muitos bibliotecários que vão atuar no ambiente escolar desenvolvem habilidades específicas para atuar nesse ambiente a partir de cursos de especialização, continuidade de estudos ou iniciativa própria. Se a atuação do bibliotecário escolar já não se mostra uma tarefa simples, atuar com a nova geração de usuários se mostra como um desafio a mais. Como destaca Castro, "a geração de alunos que as escolas recebem atualmente está cada vez mais envolvida pelos avanços tecnológicos" (CASTRO, 2014, p. 37).

Ainda existem divergências sobre a nomenclatura adotada para designar essa nova geração, mas suas características são bastante conhecidas.Em trabalho de 2014, Castro elaborou um quadro (Quadro 1) que resume bem as definições segundo alguns autores: 


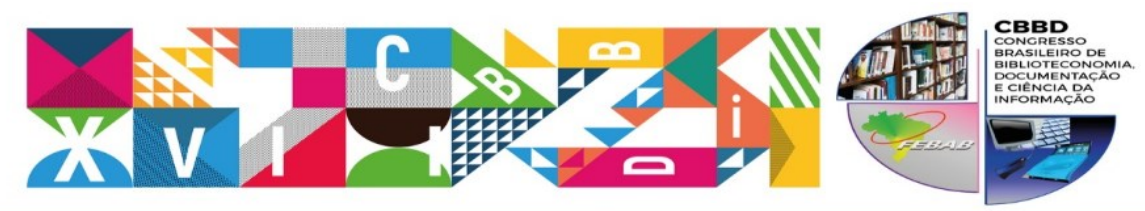

\begin{tabular}{|c|c|c|}
\hline \multicolumn{3}{|c|}{ Quadro 1 - Nomenclatura e definição da geração digital } \\
\hline Autores & Termos adotados & Definição \\
\hline Prensky (2001) & Nativos Digitais & $\begin{array}{l}\text { ‘falantes nativos' da língua digital dos } \\
\text { computadores, vídeo games e da } \\
\text { Internet }\end{array}$ \\
\hline Palfrey e Gasser (2008) & Nativos Digitais & $\begin{array}{l}\text { Aqueles que têm acesso às tecnologias } \\
\text { digitais e possuem habilidades para } \\
\text { lidar com tais tecnologias } \\
\text { Indivíduos que passam boa parte de } \\
\text { suas vidas conectados e não } \\
\text { distinguem sua vida online de sua } \\
\text { vivência off-line }\end{array}$ \\
\hline Veen e Vrakking (2006) & Homo Zappiens & $\begin{array}{l}\text { Geração que cresceu usando vários } \\
\text { dispositivos tecnológicos desde a } \\
\text { infância }\end{array}$ \\
\hline Rowlandset al (2008) & Geração Google & $\begin{array}{l}\text { Fazem parte de um grupo que não tem } \\
\text { memória da vida antes da internet }\end{array}$ \\
\hline Tapscott (1999) & Geração Net & $\begin{array}{l}\text { A primeira [geração] a crescer rodeada } \\
\text { pelas mídias digitais }\end{array}$ \\
\hline
\end{tabular}

Fonte: Adaptado de CASTRO, 2014, p. 41

Para fins desse trabalho, esses usuários serão tratados pelo termo nativos digitais,conforme sugerido porPalfrey e Gasser (2011). Os autores ressaltam que nativos digitais são aqueles que interagem de forma diferente com os outros. Eles trabalham, estudam e se relacionam geralmente mediados pela tecnologia. Assim como se relacionam de forma diversa com as amizades, eles encaram a informação de forma diversa.As características marcantes dessa geração são: aqueles nascidos depois da invenção das tecnologias da informação e da comunicação, que passam boa parte de seu tempo conectados, o que torna a diferenciação entre real e digital nem sempre clara. Como destaca Lemos (2009), essa geração é formada por sujeitos que querem as informações de forma rápida e estão acostumados a multitarefas. Assim, "os nativos digitais vivem imersos em diferentes comunidades de aprendizagens, abrindo várias janelas ao mesmo tempo" (LEMOS, 2009, p. 39).

Assim, se mostra necessário refletir sobre o imaginário do bibliotecário que irá atuar junto a essa nova geração, para que ele o possa fazer de forma eficaz. 


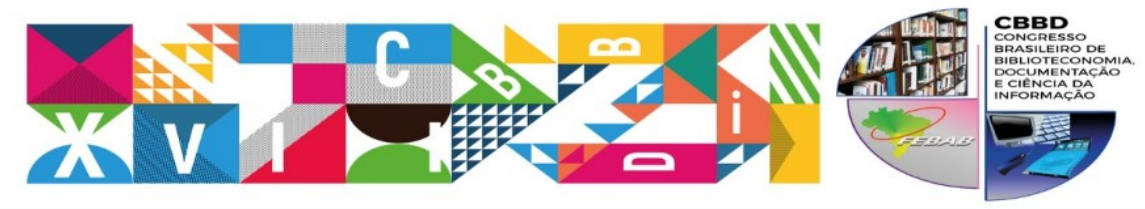

XXVII CONGRESSO BRASILEIRO DE BIBLIOTECONOMIA, DOCUMENTAÇÃO E CIÊNCIA DA INFORMAÇĀO

TEMA CENrRAL: Objetivos para o Desenvolvimento Sustentável das Naçōes Unidas:
como as bibliotecas podem contribuir com a implementaçăo da Agenda 2030

\section{A BIBLIOTECA ESCOLAR}

Como já dito, a biblioteca escolar possui sua existência e atuação intimamente ligadas à educação. Assim, as primeiras bibliotecas escolares brasileiras chegaram com os Jesuítas, mas as primeiras com as características que se conhece hoje datam da fundação das chamadas Escolas Normais, a partir de 1880 (Válio, 1990).

Dessa forma, a história da biblioteca escolar no Brasil se apresenta de forma lacunar, como também acontece com a educação. Ambas também apresentam, em certa forma, análises e atuações bastante elitistas.

Ainda que tenha surgido há vários séculos no Brasil, as discussões sobre a biblioteca escolar só se iniciam, no campo da Biblioteconomia, a partir da metade do século XX. Somente a partir desse momento se sinaliza a importância de adequar a criação das bibliotecas às necessidades educacionais.

Essa mudança de postura pode ser comprovada ao se analisar os conceitos de biblioteca escolar ao longo das décadas, juntamente aos conceitos de educação vigente. Assim, as bibliotecas escolares da década de 1970, vistas quase como depósitos de livros, acompanham um modelo de educação em que o professor e o livro-texto detinham todo o conhecimento que seria transmitido aos alunos. Em um salto de 40 anos, hoje a educação não vê o aluno como um mero recipiente, aberto e esperando para ser preenchido pelo conhecimento do mestre e do livro didático.

A partir do momento em que a educação passou a ver o aluno e a forma de ensinar de outro modo, também a biblioteca necessita se adequar a essa nova realidade.

A biblioteca, nesse contexto, deve atuar de forma a apoiar o processo de ensinoaprendizagem, e o bibliotecário, em uma atuação ideal, deveria atuar de forma integrada ao corpo docente.

\section{O BIBLIOTECÁRIO NO CONTEXTO ESCOLAR}

O bibliotecário atuante no contexto escolar deve estar disposto a servir como catalisador e mediador da informação, de forma dinâmica e integrada à atuação 


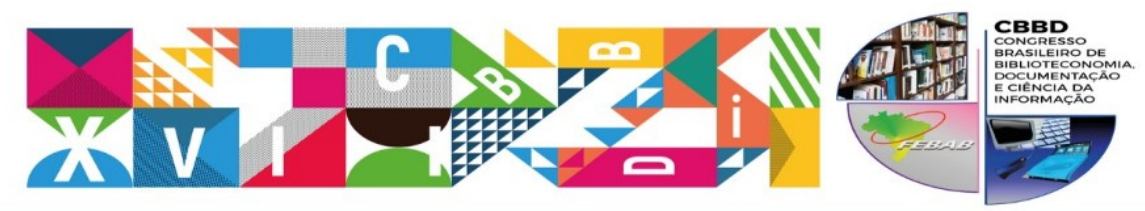

XXVII CONGRESSO BRASILEIRO DE BIBLIOTECONOMIA,

DOCUMENTAÇÃO E CIÊNCIA DA INFORMAÇÃO

TEMA CENTraL: Objetivos para o Desenvolvimento Sustentável das Naçōes Unidas:
como as bibliotecas podem contribuir com a implementaçăo da Agenda 2030

pedagógica dos docentes. Assim, ele deveria dominar não apenas as técnicas biblioteconômicas, mas também ter noções da área da educação. Isso se deve ao fato de tais profissionais atuarem também como educadores, premissa que deveria acompanhar esses sujeitos.

Contudo,

deve estar atento, não confundindo sua função, ou seja, ter bem definido quem é o professor e quem é o bibliotecário, pois o bibliotecário não foi preparado para ser professor assim como o professor não foi preparado para ser bibliotecário (ELLWEIN, 2006, p. 91).

Ser educador não significa ser professor, mas ser capaz de atuar em parceria ou em colaboração com o professor, promovendo, dessa maneira, a educação integral do aluno. Sabe-se que a atuação do bibliotecário no ambiente escolar nem sempre é fácil. A pesquisa de Morais (2009) ${ }^{1}$ destaca que todos as bibliotecários entrevistados afirmaram não terem sido preparados na graduação para coordenarem bibliotecas escolares. Silveira (2007) já delineava, ao pesquisar a questão da formação do bibliotecário no Brasil, que

(...)o ensino de Biblioteconomia no Brasil optou, isto é uma característica histórica, por formar profissionais capacitados tecnicamente para o processamento e gestão dos acervos preservados em uma unidade de informação, em detrimento do exercício de capacitá-los a compreender criticamente a importância que seu ofício assume no processo de construção das muitas esferas de atuação humana (SILVEIRA, 2007, p. 194).

Em contrapartida, Campello (2009) enfatiza haver por parte dos bibliotecários escolares a consciência de seu papel como educadores, para além das funções técnicas que necessitam desempenhar. Entretanto, enfrentam dificuldades, que vão desde o número reduzido de pessoas em sua equipe até o desconhecimento, por parte do corpo docente das funções que o bibliotecário deve (ou não) desempenhar.

\footnotetext{
${ }^{1}$ Morais (2009) pesquisa em seu trabalho a atuação de profissionais nas bibliotecas da rede municipal de Belo Horizonte. Sua pesquisa abrangeu todos os profissionais atuantes neste espaço. 0 trabalho pôde delinear um painel das bibliotecas da rede municipal da capital mineira. Dentre os resultados obtidos, foi apontada a necessidade de se rever as visões do corpo docente sobre o espaço da biblioteca e suas possibilidades.
} 


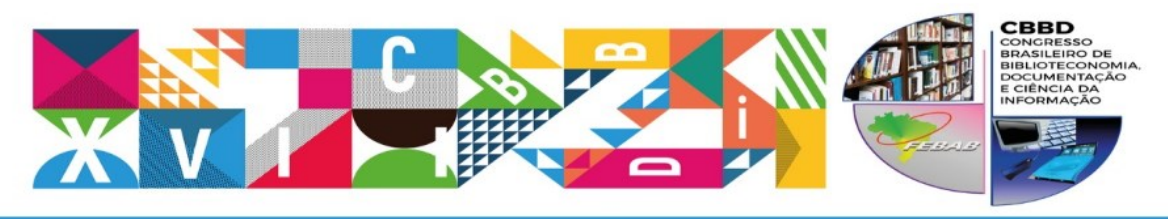

XXVII CONGRESSO BRASILEIRO DE BIBLIOTECONOMIA, DOCUMENTAÇÃO E CIÊNCIA DA INFORMAÇÃO

TEMA CENTraL: Objetivos para o Desenvolvimento Sustentável das Naçōes Unidas:
como as bibliotecas podem contribuir com a implementaçăo da Agenda 2030

Em sua atuação na biblioteca escolar o bibliotecário necessita, inicialmente, de sensibilizar e conquistar o usuário. Para tal devem predominar as ações que atraem a comunidade escolar para a biblioteca e para a leitura.

Furtado (2002) destaca a necessidade da interação entre corpo docente e equipe da biblioteca, o que nem sempre ocorre. A integração entre bibliotecário e professor melhoraria os trabalhos dos dois segmentos (ALVES, 1992; MOTA, 2004, MORAIS, 2009, FÉLIX, 2014). Contudo, o estudo realizado por Alves (1992) mostrou que a questão da integração entre os dois profissionais, ainda que promissora, é falha, superficial e está longe de promover a colaboração de forma efetiva para ambos.

Em artigo publicado em 1988, Murilo Bastos da Cunha fala na necessidade de mudança na postura do bibliotecário, sendo premente que ele assuma seu papel como educador. Contudo, como salienta Soares (2014), o papel educador do bibliotecário é debatido desde o século XIX, através dos Serviços de Referência. Ainda assim, como identificado por Campello (2009), o papel educativo do bibliotecário brasileiro, ainda que apareça em discurso desde 1960, não reflete a prática. E um dos principais entraves para esse papel ser desempenhado de forma mais eficiente é a falta de entrosamento entre o bibliotecário e o professor, como já mencionado.

Aliado a todas essas questões inerentes ao trabalho no ambiente escolar, o bibliotecário deve, também, se preocupar com as necessidades dos alunos, essa nova geração de sujeitos presentes nas escolas atualmente. Em pesquisa de doutoramento que se encontra em fase de conclusão, temos obtido resultados preliminares que demonstram que os nativos digitais concebem a biblioteca como espaço de leitura para fruição, não a relacionam de forma alguma com um local onde podem encontrar informações utilitárias ou de pesquisa. Quando possuem um trabalho, tarefa ou pesquisa escolar, as crianças e jovens dessa geração usam, prioritariamente, seus smartphones como recurso para o processo de busca de informação. A biblioteca não é mencionada por eles como um local para efetuar esse processo.

A pergunta adjacente, que gerou a presente pesquisa, foi: e o bibliotecário escolar, que representa esse espaço que está sendo negligenciado como espaço ou recurso para busca informacional, qual é a visão que este profissional possui do seu usuário? 


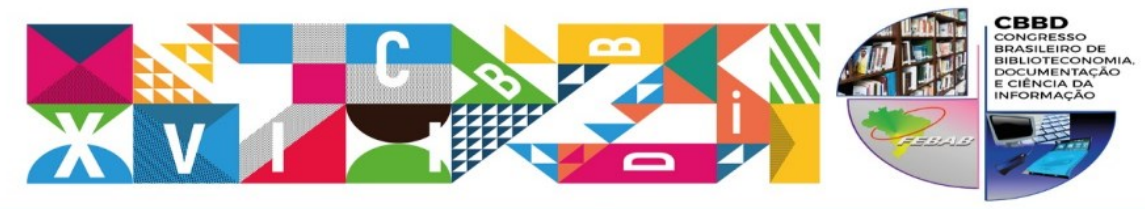

XXVII CONGRESSO BRASILEIRO DE BIBLIOTECONOMIA,

DOCUMENTAÇÃO E CIÊNCIA DA INFORMAÇÃO

TEMA CENIral: Objetivos para o Desenvolvimento Sustentável das Naçōes Unidas:
como as bibliotecas podem contribuir com a implementaçăo da Agenda 2030

\section{MÉTODO DA PESQUISA}

0 trabalho utilizou um experimento de associação de palavras, a fim de conhecer melhor o imaginário do bibliotecário escolar. 0 método foi desenvolvido na psicologia e bastante utilizado por Jung para explorar os complexos dos sujeitos estudados. Segundo Jung (1962), o experimento de associação de palavras pode servir como o caminho de acesso ao inconsciente.

0 experimento possui todo um método a ser seguido. Inicialmente o pesquisador (ou experimentador) dispõe de uma lista de palavras, chamadas aqui palavras-indutoras, escolhidas ao acaso, sem relações de significados. Essa falta de relação entre as palavras é bastante importante para o sucesso do experimento. Isso se deve ao fato de essa lista não dever apresentar nenhuma sugestão de reação ao sujeito.

As palavras são apresentadas uma após a outra ao sujeito, que é convidado a reagir a cada palavra que lhe for sugerida com uma outra palavra ou termo: a primeira palavra que lhe vier à mente, o mais rápido quanto possível.

0 experimentador fica de posse de um cronômetro, para medir o tempo de reação a cada palavra-indutora. 0 tempo decorrido entre o término da pronúncia do experimentador e o início da resposta do sujeito é marcado/anotado e chamado de tempo de reação. 0 tempo de reação varia de pessoa para pessoa, assim, para a análise de incidentes decorrente de demora na resposta é necessário determinar a mediana de tempo. A mediana é utilizada ao invés da média aritmética, a fim de evitar alterações por termos com valores excessivamente altos. Dessa forma, a mediana, ou média provável se aproxima mais da realidade.

A lista inicial de palavras-indutoras contém cerca de 100 palavras. Após a primeira rodada, segue-se com uma segunda fase, onde sujeito é convidado a reagir novamente à lista de termos, buscando repetir a mesma palavra de reação informada por elena primeira rodada. Nessa segunda fase não há medição do tempo de reação, já que o objetivo agora é testar se o sujeito lembra-se ou não da resposta que deu anteriormente. 


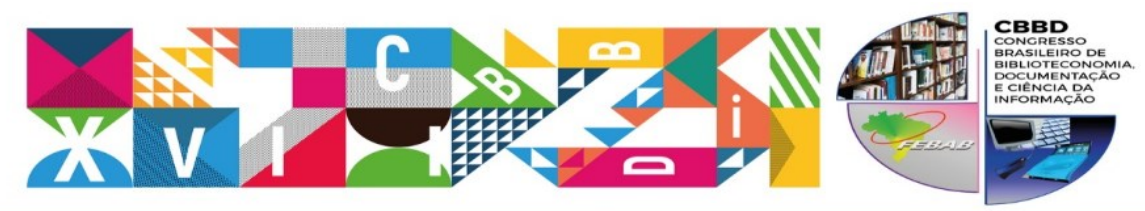

XXVII CONGRESSO BRASILEIRO DE BIBLIOTECONOMIA, DOCUMENTAÇÃO E CIÊNCIA DA INFORMAÇĀO

TEMA CENrRaA: Objetivos para o Desenvolvimento Sustentável das Naçōes Unidas:
como as bibliotecas podem contribuir com a implementaçâo da Agenda 2030

Todos os incidentes que podem ocorrer, como a demora na resposta, a falta de resposta, reações estranhas a determinadas palavras, troca de palavras na repetição.Todos esses elementos podem ser analisados à luz da teoria dos complexos (grupos de ideias inconscientes associadas a eventos ou experiências particulares). Essas perturbações aparecem como um conteúdo emocional, presente no inconsciente do sujeito.

Após o registro das reações do sujeito há uma série de aspectos que podem ser analisados, sendo o primeiro o tempo de reação. Para se realizar uma análise mais precisa é estabelecida uma mediana do tempo de resposta do sujeito. A partir dessa mediana é que será possível detectar os desvios presentes.

Após a realização do experimento, o sujeito é convidado a realizar uma entrevista, a fim de se verificar os termos que apresentaram algum tipo de reação. Pode-se detectar cerca de 14 (quatorze) tipos de reações, que devem ser analisadas somente após o esclarecimento dado pela entrevista.

Durante o experimento, também é importante perceber e registrar todas as reações físicas que o sujeito participante apresentar. Essas reações, muitas vezes incontroláveis e imperceptíveis para o experimentado, são excelentes indícios para o experimentador.

Assim, para fins deste trabalho, o experimento de associação de palavras foi realizado com uma bibliotecária que atua no contexto escolar há cerca de 7 anos. Foi apresentada uma lista com 101 palavras-estímulo, seguida pela repetição. Em um momento posterior, foi realizada uma entrevista pra elucidar algumas questões detectadas pela análise dos dados.

As pesquisas desenvolvidas por Jung e seus seguidores desenvolveram uma lista padrão de palavras mas, para a realização do experimento, optou-se por modificar alguns termos a fim de checar o imaginário do sujeito diante do universo da biblioteca escolar e dos nativos digitais.

\section{RESULTADOS}



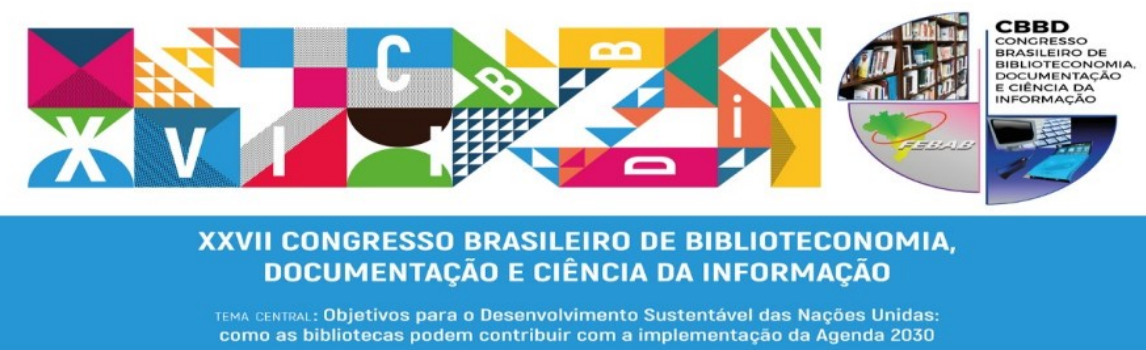

Após a realização do experimento, as medições de reação ofereceram os tempos de repostas que possibilitaram determinar a mediana de tempo de reação. Nas primeiras 50 palavras ela é 2 milésimos de segundo. A mediana das 51 palavras restantes foi a mesma, demonstrando que o cansaço não influenciou. Destaca-se que as palavras que tiveram maior tempo de reação (novidade, com 18,3 milésimos de segundo e injusto, com 11,8 milésimos de segundo) encontram-se entre as 50 primeiras palavras, sendo a 47 ạe a 50 a ,respectivamente.

Fazendo uma análise inicial dos indicadores de reação encontramos sete reações nas primeiras 50 palavras, com tempo de reação prolongado. Nas 51 seguintes foram oito reações com tempo prolongado, valor parecido com a primeira metade do experimento. O quadro 2 apresenta as palavras-estímulo com tempo de reação prolongado, sendo que elas são apresentadas na ordem cronológica em que foram apresentadas na pesquisa. 0 tempo prolongado nas reações tende a demonstrar situações com as quais a pesquisada possa ter dificuldades ou problemas, já que é necessário que ela reflita mais a esse respeito.

Quadro 2: Indicadores e tempo de reação em situações com tempo prolongado

\begin{tabular}{|c|c|c|c|c|c|}
\hline \multicolumn{3}{|c|}{ 1- metade da pesquisa (palavras 1 a 50 ) } & \multicolumn{3}{|c|}{ 2a metade da pesquisa (palavras 51 a 101) } \\
\hline $\begin{array}{l}\text { Palavra } \\
\text { Estímulo }\end{array}$ & Resposta & $\begin{array}{l}\text { Tempo de } \\
\text { reação (em } \\
\text { milisegundos) }\end{array}$ & $\begin{array}{l}\text { Palavra } \\
\text { Estímulo }\end{array}$ & Resposta & $\begin{array}{l}\text { Tempo de } \\
\text { reação (em } \\
\text { milisegundos) }\end{array}$ \\
\hline Cantar & $\begin{array}{c}\text { Tavinho } \\
\text { Leone }\end{array}$ & 9.9 & Voraz & Agressivo & 6.4 \\
\hline Doente & $\begin{array}{c}\text { Situação } \\
\text { difícil }\end{array}$ & 5.4 & Discutir & $\begin{array}{c}\text { Sem } \\
\text { paciência }\end{array}$ & 5.4 \\
\hline Cozinhar & $\begin{array}{c}\text { Comer é } \\
\text { melhor }\end{array}$ & 4.0 & Parede & Casa & 4.3 \\
\hline Jornada & Empreitada & 7.8 & Derrotar & Ganhar & 4.0 \\
\hline Costume & Ler & 4.1 & Temer & Morte & 4.8 \\
\hline Novidade & Algo novo & 18.3 & Puro & Leite & 4.7 \\
\hline \multirow[t]{2}{*}{ Injusto } & Política & 11.8 & Ridículo & $\begin{array}{c}\text { Tênis } \\
\text { verde }\end{array}$ & 4.4 \\
\hline & & & Abusar & $\begin{array}{c}\mathrm{Da} \\
\text { paciência }\end{array}$ & 8.4 \\
\hline
\end{tabular}

Fonte: dados da pesquisa (2017). 

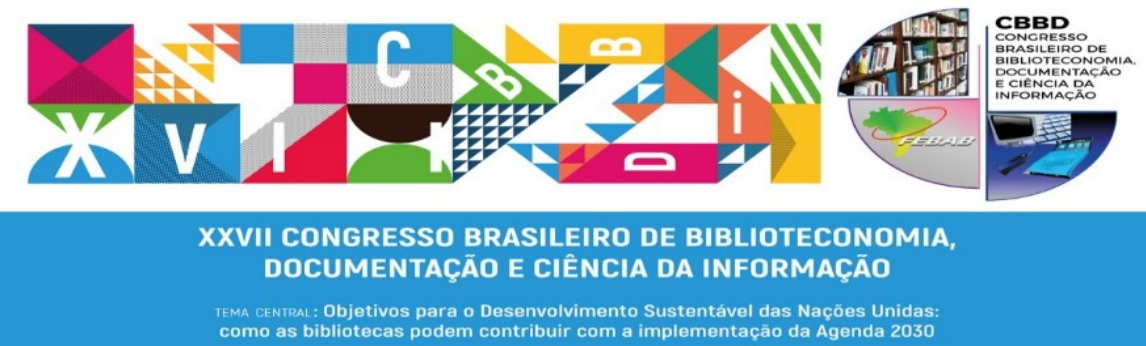

Uma análise inicial desses dados pode levar a pensar que a entrevistada tem uma certa dificuldade com mudanças, considerando que a palavra-estímulo com maior tempo de reação entre todas foi exatamente novidade.Depois de pensar, a entrevistada respondeu comalgo novo, mas reclamou que nada lhe vinha à cabeça. A palavra que antecedeu essa foi caro, que foi respondida dentro da mediana com o termo barato, uma mera associação de significados (neste caso o uso de antônimo).

Na entrevista posterior com a pesquisada, ela disse que não tem problemas com mudanças e novidades, que a dificuldade em responder alguns termos se deveu ao cansaço em geral em que se encontrava. Contudo, ao se analisar os termos, podemos correlacionar sua demora com as palavras jornada, costume, novidade, derrotar e temer. Foram termos que demandaram mais tempo de reação, em alguns casos, bem superior à mediana. No caso de jornada, que foi associada aempreitada, a pesquisada alegou posteriormente, na entrevista, que sua jornada de trabalho daquele dia havia sido muito exaustiva e estressante, justificando deste modo a associação feita.

A reação seguinte notada foi a complementação da palavra-estímulo. Apareceu três vezes na primeira metade do experimento e sete vezes na segunda metade, conforme apresentado no Quadro 3. Essa reação denota certa "concordância" inconsciente por parte do sujeito, que não tenta opor-se ao termo sugerido nem associar novo termo, mas apenas complementá-lo, numa espécie de submissão ao que foi proposto. Pode-se notar que, no caso do termo abusar, além da concordância ou submissão, nota-se um tempo de reação excessivo, o que pode sugerir que a pesquisada está com problemas em relação ao abuso de sua própria paciência. Os termos imediatamente anteriores e posteriores da lista foram respondidos de forma imediata com curto tempo de resposta, o que demonstra que o termo abusar realmente perturbou a bibliotecária. Além disso, no momento da repetição dos termos, ela repetiu corretamente a sua resposta, reforçando a relação que percebe entre abuso e paciência.

Quadro 3 - Reações em situação de complementação da palavra-estímulo

$1^{\text {a }}$ metade da pesquisa (palavras 1 a 50)

$2^{\text {a }}$ metade da pesquisa (palavras 51 a 101) 

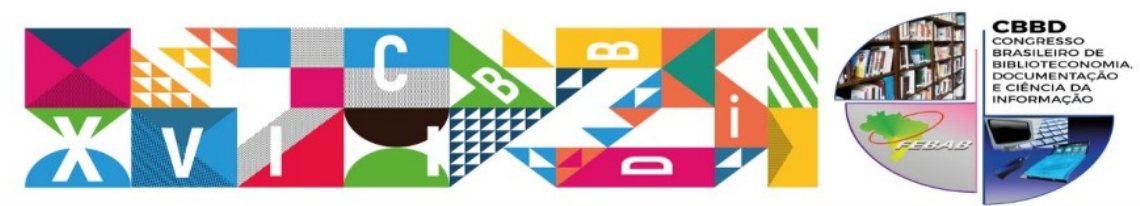

\begin{tabular}{|c|c|c|c|c|c|}
\hline \multicolumn{6}{|c|}{$\begin{array}{l}\text { XXVII CONGRESSO BRASILEIRO DE BIBLIOTECONOMIA, } \\
\text { DOCUMENTAÇÃ̄O E CIÊNCIA DA INFORMAÇĀOO } \\
\text { TEMA cENIRAL: Objetivos para o Desenvolvimento Sustentável das Naçōes Unidas: } \\
\text { como as bibliotecas podem contribuir com a implementaçăo da Agenda } 2030\end{array}$} \\
\hline $\begin{array}{l}\text { Palavra } \\
\text { Estímulo }\end{array}$ & Resposta & $\begin{array}{l}\text { Tempo de } \\
\text { reação (em } \\
\text { milisegundos) }\end{array}$ & $\begin{array}{l}\text { Palavra } \\
\text { Estímulo }\end{array}$ & Resposta & $\begin{array}{l}\text { Tempo de } \\
\text { reação (em } \\
\text { milisegundos) }\end{array}$ \\
\hline Pagar & $\begin{array}{l}\text { Quando } \\
\text { receber }\end{array}$ & 2.4 & $\begin{array}{l}\text { Prestar } \\
\text { atenção }\end{array}$ & $\begin{array}{c}\text { Nas } \\
\text { normas }\end{array}$ & 2.4 \\
\hline Educação & Vem de casa & 2.2 & Caixa & $\begin{array}{c}\text { De } \\
\text { presente }\end{array}$ & 2.1 \\
\hline \multirow[t]{5}{*}{ Pão } & De queijo & 1.1 & Escutar & É preciso & 2.6 \\
\hline & & & Facebook & Tenho & 1.4 \\
\hline & & & Regra & $\begin{array}{l}\text { Para ser } \\
\text { seguida }\end{array}$ & 0.9 \\
\hline & & & Porta & Aberta & 2.2 \\
\hline & & & Abusar & $\begin{array}{c}\mathrm{Da} \\
\text { paciência }\end{array}$ & 8.4 \\
\hline
\end{tabular}

Fonte: dados da pesquisa (2017).

As reações longas, que tomam forma de várias palavras ou de frase inteira apareceram bastante, sendo 11 em cada parte da pesquisa (Quadro 4). Essa reação denota que o sujeito não se ateve às orientações dadas no começo do experimento. Pode também ser encarada como uma forma de burlar a reação causada pelo termo indutor. Assim, pode-se verificar que termos como caixa e pão são respondidas com termos longos, apenas complementaresà ideia inicial, podendo denotar realmente uma resposta sem preocupação. Já termos como educação, prestar atenção, discutir, silêncio, nativo digital, adolescência, possuem reações que podem demonstrar mais que uma situação de desrespeito às orientações iniciais. Ao relacionar educação com a resposta vem de casa, adolescência com teste de paciência, nativo digital com crianças de hoje, pode-seinferir que o sujeito está com certa dificuldade em lidar com os nativos digitais presentes hoje na escola, que representam um teste de paciência para os profissionais, talvez por falta da educação que não veio de casa. Lembrando que o termo abusar que levou à respostada paciência, também apresentou um tempo elevado de reação, além de se apresentar como mera complementação de ideia, para compor o significado.

Quadro 4 - Reações longas

\begin{tabular}{|l|l|}
\hline $1^{\underline{a}}$ metade da pesquisa (palavras 1 a 50$)$ & $2^{\text {a }}$ metade da pesquisa (palavras 51 a 101) \\
\hline
\end{tabular} 


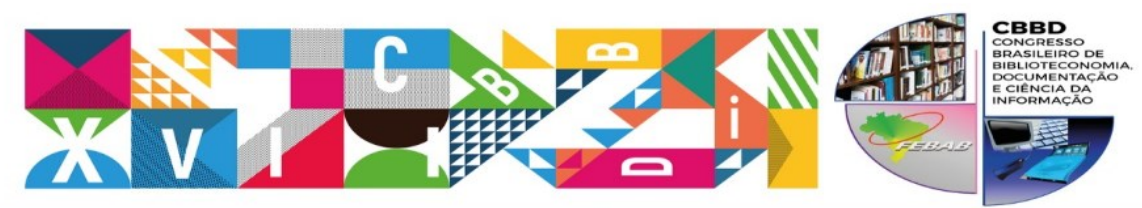

\begin{tabular}{|c|c|c|c|}
\hline \multicolumn{4}{|c|}{$\begin{array}{l}\text { XXVII CONGRESSO BRASILEIRO DE BIBLIOTECONOMIA, } \\
\text { DOCUMENTAÇÃOO E CIÊNCIA DA INFORMAÇĀO } \\
\text { TEMA cENTrAL: Objetivos para o Desenvolvimento Sustentável das Naçōes Unidas: } \\
\text { como as bibliotecas podem contribuir com a implementaçăo da Agenda } 2030\end{array}$} \\
\hline $\begin{array}{l}\text { Palavra } \\
\text { Estímulo }\end{array}$ & Resposta & $\begin{array}{l}\text { Palavra } \\
\text { Estímulo }\end{array}$ & Resposta \\
\hline Pagar & Quando receber & Prestar atenção & Nas normas \\
\hline Amigável & Colegas de trabalho & Discutir & Sem paciência \\
\hline Educação & Vem de casa & Silêncio & $\begin{array}{c}\text { Bom, mas sinto falta do } \\
\text { barulho }\end{array}$ \\
\hline Adolescência & Teste de paciência & Caixa & De presente \\
\hline Doente & Situação difícil & Escutar & É preciso \\
\hline Orgulho & Ser bibliotecária & Regra & Para ser seguida \\
\hline Cozinhar & Comer é melhor & YouTube & Quase não vejo \\
\hline Bravo & Eu às vezes... & Satisfeito & Meu salário \\
\hline Pão & De queijo & Ridículo & Tênis verde \\
\hline Nativo Digital & Criança de hoje & Dormir & Ai... Muito! \\
\hline Novidade & Algo novo & Abusar & Da paciência \\
\hline
\end{tabular}

Fonte: dados da pesquisa (2017).

Após a análise geral, foi possível perceber que algumas palavras indutoras apresentam mais de uma reação, sendo 08 na primeira metade e 08 na segunda. Destas, apenas a palavra indutora abusar gerou 3 reações e as demais foram 2 reações. Termos que geram mais de uma reação, são, certamente, os que mais sinalizam dados a serem analisados do inconsciente do sujeito. Das palavras que geraram mais de um complexo, para fins desse trabalho vamos destacar Educação, Nativo Digital, Novidade, Prestar atenção,Escutar e Regra. Inicialmente todas foram respondidas com frases longas, conforme se vê no quadro 4, contudo, esses termos geraram outras reações, principalmente a complementação da ideia, como nos casos de Educação - vem de casa, prestar atenção - nas normas, escutar - é preciso, regra - para ser seguida. Infere-se que a pesquisada pode, com essa atitude, tentar burlar seus reais sentimentos frente a essas questões, que incluem a dificuldade de lidar com:

(1) a novidade, a saber os nativos digitais frente a questão da educação, vista como os valores que vêm de casa e não os conhecimentos adquiridos na escola;

(2) a dificuldade desse público em escutar, em prestar atenção às normas (ou regras).

$\mathrm{Na}$ segunda parte do experimento, quando se solicitou que a pesquisada procurasse repetir suas respostas dadas às palavras-estímulo, apareceram 10 respostas diferentes das originais, sendo 05 em cada parte do teste (Quadro 5). Essa mudança nas 

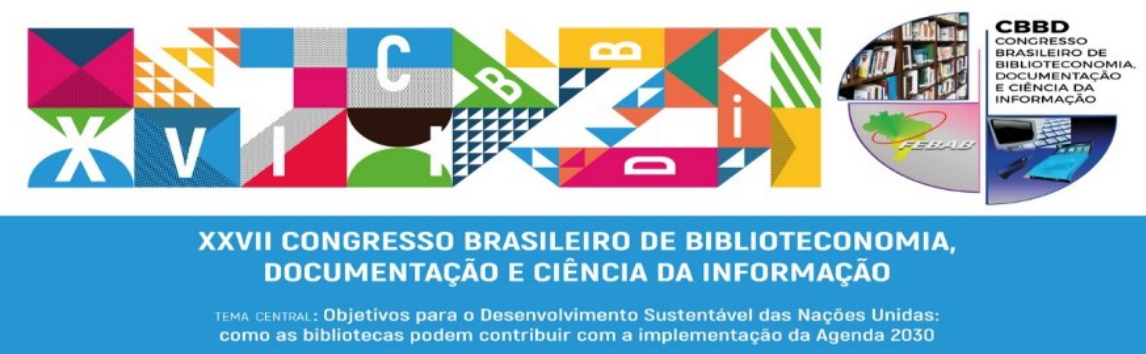

respostas,em que ela percebe e reclama mais na segunda parte do teste, pode denotar o cansaço da pesquisada frente ao experimento. Somente no caso do termo milhoocorre uma situação completamente diferente, pois a bibliotecária sequer lembrava do termo ter sido citado na primeira rodada.

Quadro 5 - Respostas diferentes na segunda parte do experimento

\begin{tabular}{|c|c|c|c|c|c|}
\hline \multicolumn{3}{|c|}{$1^{\mathrm{a}}$ metade da pesquisa (palavras 1 a 50 ) } & \multicolumn{3}{|c|}{$2^{\mathrm{a}}$ metade da pesquisa (palavras 51 a 101 ) } \\
\hline $\begin{array}{l}\text { Palavra } \\
\text { Estímulo }\end{array}$ & $\begin{array}{l}\text { Resposta na } 1^{\mathrm{a}} \\
\text { parte do } \\
\text { experimento }\end{array}$ & $\begin{array}{l}\text { Resposta na } 2^{\mathrm{a}} \\
\text { parte do } \\
\text { experimento }\end{array}$ & $\begin{array}{l}\text { Palavra } \\
\text { Estímulo }\end{array}$ & $\begin{array}{l}\text { Resposta na } \\
1^{\text {a }} \text { parte do } \\
\text { experimento }\end{array}$ & $\begin{array}{l}\text { Resposta na } 2 \\
\text { parte do } \\
\text { experimento }\end{array}$ \\
\hline Tecnologia & Acessibilidade & Computador & Voraz & Agressivo & $\begin{array}{l}\text { Esqueceu e } \\
\text { disse que } \\
\text { achava ser } \\
\text { feroz }\end{array}$ \\
\hline Computador & Tecnologia & Internet & Derrotar & Ganhar & Vencer \\
\hline Jovem & Criança & Paciência & Felicidade & Férias & $\begin{array}{l}\text { Meu salário! } \\
\text { Não! Foi } \\
\text { férias! }\end{array}$ \\
\hline Amarelo & Milho & Ouro & Regra & $\begin{array}{l}\text { Para ser } \\
\text { seguida }\end{array}$ & Norma \\
\hline Estúpido & Ignorância & Grosseiro & Falso & Mentiroso & $\begin{array}{c}\text { Não me } \\
\text { lembro, vou } \\
\text { falar mentira }\end{array}$ \\
\hline
\end{tabular}

Fonte: dados da pesquisa (2017).

\section{DISCUSSÃo}

O método da associação de palavras foi utilizado a fim de buscar as reações, pensamentos e sentimentos da pesquisada sobre a atuação na biblioteca escolar e sobre os nativos digitais, ou seja, os alunos hoje presentes nas escolas. Uma análise rápida do experimento demonstra que a pesquisada gosta do que faz, tem orgulho da profissão escolhida e se sente bem em sua atuação, uma vez que ao termos orgulho foi associado à ser bibliotecária, satisfeito com meu salário e biblioteca à lar. Em contrapartida, vê algumas dificuldades na atuação na escola, por exemplo, no que diz respeito ao barulho, cujo termo, ao ser apresentado, foi associado à escola onde a mesma atua.

Campello (2009) destaca que o papel do bibliotecário atualmente vai além do incentivo à leitura, necessitando que esse profissional contribua para uma formação mais 


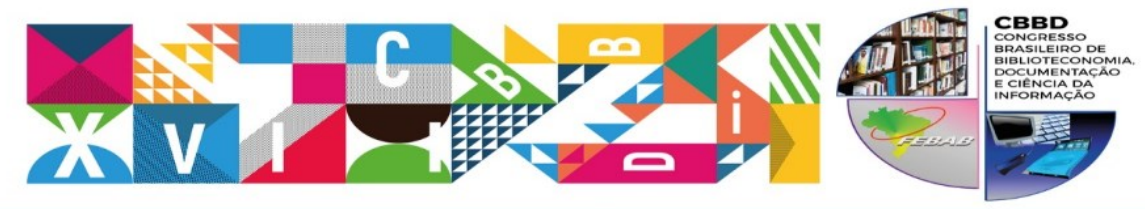

XXVII CONGRESSO BRASILEIRO DE BIBLIOTECONOMIA, DOCUMENTAÇÃO E CIÊNCIA DA INFORMAÇÃO

TEMA CENIRal: Objetivos para o Desenvolvimento Sustentável das Naçōes Unidas:
como as bibliotecas podem contribuir com a implementaçăo da Agenda 2030

complexa. Aliado a isso Castro (2014) destaca a necessidade de que o profissional esteja ciente de que na escola se encontra uma nova geração de alunos, os nativos digitais. $\mathrm{Ou}$ seja, é necessário aliar o conhecimento técnico a uma abordagem pedagógica e alinhada a esse usuário.

No experimento foi possível perceber que a bibliotecária tem preocupações com os jovens e as crianças, mas não possui uma relação muito próxima às novas tecnologias. Ao termo Facebook respondeu tenho, enquanto a YouTube foi a expressão quase não vejo. Nota-se, ainda, que ao termo educação respondeu vem de casa e ao termo ensinar associou àprofessor, ou seja, a educação é vista como os valores do aluno e não sua formação acadêmica, formação esta que deve ser dada pelo professor no ambiente da escola.

Uma reação que se destacou e pode se relacionar a um complexo latente foi a palavra amarelo, que na primeira rodada foi respondida com milho, resposta que foi completamente esquecida pela pesquisada na hora da repetição. Durante a entrevista, realizada posteriormente e em dia diferente da aplicação da lista de termos, ela relatou que tal situação a incomodou muito, por sequer lembrar que a palavra amarelohavia sido induzida antes. A palavra-estímulo imediatamente anterior a amarelofoi jovem, que na primeira rodada foi associada acriança e na repetição também levou a erro, pois foi associadaapaciência. Esse ato falho e a palavra seguinte esquecida pode demonstrar um complexo da pesquisada com relação ao universo infanto-juvenil.

Ainda que a entrevistada goste do que faz, tenha orgulho da sua profissão, sua dificuldade com as mudanças, não apenas na rotina de trabalho, mas também no mundo tecnológico, pode causar obstáculos em lidar com esses novos alunos. Assim, o termo novidade apresentou o maior tempo de reação (18.3), seguida de uma resposta com dois termos (algo novo) e um comentário (ixi... não vem nada na cabeça) podendo indicar uma dificuldade, além é claro, da já citada pouca demonstração de relação com a tecnologia, através das respostas aos termos referentes às redes sociais.

\section{CONSIDERAÇÕES FINAIS OU CONCLUSÕES}




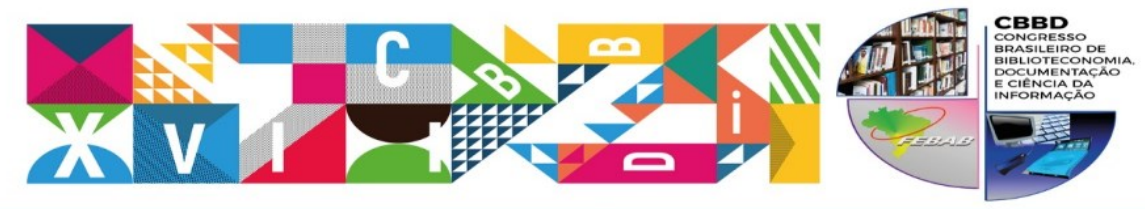

XXVII CONGRESSO BRASILEIRO DE BIBLIOTECONOMIA,

DOCUMENTAÇÃO E CIÊNCIA DA INFORMAÇÃO

TEMA CENTraL: Objetivos para o Desenvolvimento Sustentável das Naçōes Unidas:
como as bibliotecas podem contribuir com a implementaçăo da Agenda 2030

O presente trabalho se dispôs a verificar o imaginário de uma bibliotecária escolar com relação aos nativos digitais, a partir do experimento de associação de palavras. Acredita-se que o objetivo foi parcialmente atendido, devido à limitação clara de que o experimento foi realizado com uma única bibliotecária. Sugere-se que mais pesquisas sejam desenvolvidas no sentido de compreender seja o imaginário seja a percepção consciente dos bibliotecários escolares em relação aos seus usuários atuais.

Conclui-se que a bibliotecária investigada tem orgulho e gosta do que faz, o que é importante para uma atuação voltada para atender às demandas e necessidades dos usuários. Esses usuários são, em sua maioria² ${ }^{2}$ jovens e crianças em processo de formação e que possuem uma relação bastante distinta com o universo da informação e da leitura. Como destacado pelos autores que pesquisam os nativos digitais, essa geração se mostra bastante conectada, chegando a considerar o real e o virtual como a mesma realidade. Assim, os bibliotecários no contexto escolar terão que, além de se adequar a seu papel de educar, buscar conhecer e utilizar as novas tecnologias e as redes sociais. A bibliotecária pesquisada demonstrou não estar muito à vontade com essas questões, uma vez que Facebook e YouTube não se mostraram como pertencentes ao seu cotidiano.

Diante dessa perspectiva, nota-se que esse público ainda não é plenamente compreendido, causando uma preocupação latente. Assim, se sugere a ampliação de trabalhos que investiguem os nativos digitais no ambiente da escola e da biblioteca escolar, além de debates e reflexões dos bibliotecários que atuam no contexto escolar.

\section{REFERÊNCIAS}

ALVES, Miriam Cristina. A integração bibliotecário-professor no Brasil: o estado da arte. 1992. [105]f. Dissertação (Mestrado) Faculdade de Biblioteconomia, Pontifícia Universidade Católica De Campinas, Campinas, 1992.

BRASIL. Congresso. Lei n.o 12.244, de 24 de maio de 2010. Dispõe sobre a universalização das bibliotecas nas instituições de ensino do País. Diário Oficial [da] República Federativa do Brasil, Poder Executivo, Brasília, DF, 25 maio 2010. Seção 1, 2010.

CAMPELLO, Bernadete Santos. Letramento informacional: função educativa do bibliotecário na escola. Belo Horizonte: Autêntica, 2009. (Coleção Biblioteca Escolar).

\footnotetext{
${ }^{2}$ Também usam a biblioteca escolar os professores e os demais integrantes da comunidade escolar e, em alguns casos, os estudantes não são crianças ou jovens.
}

Revista Brasileira de Biblioteconomia e Documentação - v. 13, n. esp. CBBD 2017 


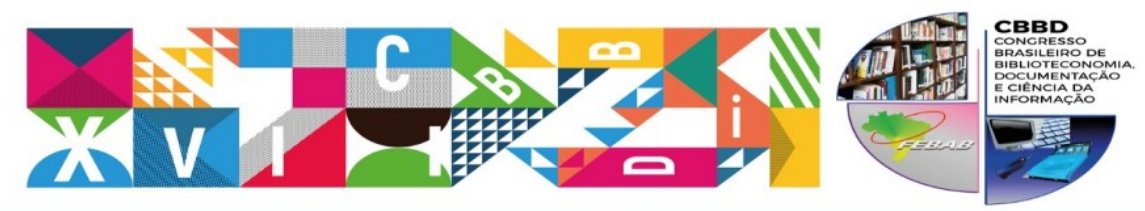

XXVII CONGRESSO BRASILEIRO DE BIBLIOTECONOMIA, DOCUMENTAÇÃO E CIÊNCIA DA INFORMAÇĀO

TEMA CENTRAL: Objetivos para o Desenvolvimento Sustentável das Naçōes Unidas:
como as bibliotecas podem contribuir com a implementaçăo da Agenda 2030

CASTRO, Jaqueline F.S. de. Nativos Digitais na biblioteca escolar: programas de letramento informacional para o ensino médio. 2014. Dissertação (Mestrado em Mestrado Profissional em Biblioteconomia) - Universidade Federal do Estado do Rio de Janeiro, Rio de Janeiro, 2014.

ELLWEIN, S. A. F. Pesquisa escolar e o enfadonho exercício de cópia: como separar o trigo do joio? In: SILVA, R. J.; BORTOLIN, S. (Org.). Fazeres cotidianos na biblioteca escolar. São Paulo: Polis, 2006. p. 79-96. (Coleção Palavra-Chave, v.17).

FÉLIX, Andreza Ferreira. Práticas educativas em bibliotecas escolares: a perspectiva da cultura escolar - uma análise de múltiplos casos na RME/BH. 2014. 124 f. Dissertação (mestrado) - Universidade Federal de Minas Gerais, Escola de Ciência da Informação. Disponível em: <http://hdl.handle.net/1843/BUOS-9UFN8D>. Acesso em: 01/04/2015.

FURTADO, Cássia. A biblioteca escolar brasileira no sistema educacional da sociedade da informação. In: SEMINÁRIO BIBLIOTECA ESCOLAR ESPAÇO DE AÇÃO PEDAGÓGICA, 2004, Belo Horizonte. ANAIS DO SEGUNDO SEMINÁRIO BIBLIOTECA ESCOLAR ESPAÇO DE AÇÃO PEDAGÓGICA, 2004. Disponível em: < http://gebe.eci.ufmg.br/downloads/317.pdf>. Acesso em: $15 / 04 / 2015$.

JUNG, C. G. O homem à descoberta da sua alma: estrutura e funcionamento do inconsciente. Portugal: Livraria Tavares Martins, 1962.507 p.

LEMOS, Silvana. Nativos digitais $x$ aprendizagens: um desafio para a escola. B. Téc. Senac: a R. Educ. Prof., Rio de Janeiro, v. 35, n.3, set./dez. 2009.

MORAIS, Elaine Maria da Cunha. Impasses e possibilidades da atuação dos profissionais das bibliotecas da Rede Municipal de Belo Horizonte. 2009. 185 f. Dissertação. (Mestrado em Educação). Faculdade de Educação, Universidade Federal de Minas Gerais, Belo Horizonte, 2009.

MOTA, Francisca Rosalina Leite. Bibliotecários e professores no contexto da biblioteca escolar: uma interação possível e necessária. In: SEMINÁRIO BIBLIOTECA ESCOLAR ESPAÇO DE AÇÃO PEDAGÓGICA, 2004, Belo Horizonte. ANAIS DO SEGUNDO SEMINÁRIO BIBLIOTECA ESCOLAR ESPAÇO DE AÇÃO PEDAGÓGICA, 2004.

PALFREY, John; GASSER, Urs. Nascidos na era digital:entendendo a primeira geração de nativos digitais. Porto Alegre: Artmed, 2011, 352 p.

PALFREY, John, GASSER, Urs. Born digital:understandingthefirstgenerationof digital natives. New York: Basic Books, 2008. 375 p.

PRENSKY, Marc. Digital natives, digital immigrants. Onthehorizon, MCB University Press, v. 9, n. 5, p.1-6, 2001, Disponívelem: <http://www.nnstoy.org/download/technology/Digital\%20Natives\%20\%20Digital\%20Immigrants.pdf >. Acesso em: 10/09/2015.

ROWLANDS, I. et al. The Google generation: theinformationbehaviouroftheresearcherofthe future. AslibProceedings: New Information Perspectives, v. 60, n. 4, p. 290-310, 2008. 


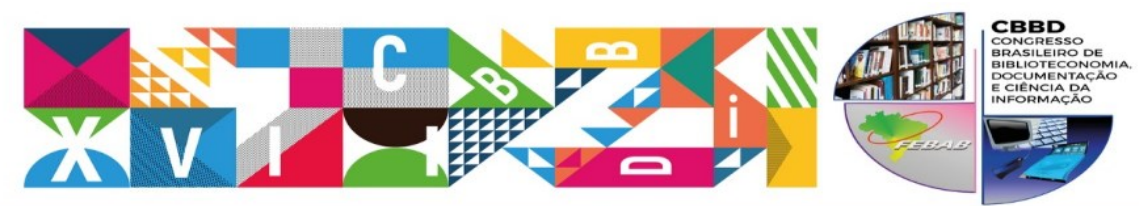

XXVII CONGRESSO BRASILEIRO DE BIBLIOTECONOMIA,
DOCUMENTAÇÃO E CIÊNCIA DA INFORMAÇÃO
TEMa cEnTras: Objetivos para o Desenvolvimento Sustentável das Naçōes Unidas:
como as bibliotecas podem contribuir com a implementação da Agenda 2030

SILVEIRA, Fabrício José Nascimento da.Biblioteca como lugar de práticas culturais: uma discussão a partir dos currículos de Biblioteconomia no Brasil. Belo Horizonte. 2007. 246 f. Dissertação (Mestrado em Ciência da Informação) - Escola de Ciência da Informação Universidade Federal de Minas Gerais, Belo Horizonte, 2007.

SOARES, Laura Valladares de Oliveira. A formação como aliada no exercício do papel educativo do bibliotecário na escola. 2014. 99 fls. Dissertação (Mestrado em Ciência da Informação) - Escola de Ciência da Informação, Universidade Federal de Minas Gerais, Belo Horizonte, 2014.

TAPSCOTT, Don. Educatingthe Net Generation. EducationalLeadership, v. 56, n. 5, p. 6-11, Feb. 1999. Disponível em: <http://www.ascd.org/readingroom/edlead/abstracts/feb99. html>. Acesso em: 19 jun. 2013.

VÁLIO, Else Benetti Marques. Biblioteca escolar: uma visão histórica.Transinformação, v. 2, n. 1, jan/abr. 1990, p. 15-24.

VEEN, Wim; VRAKKING, Ben. Homo zappiens:growingup in a digital age. London: Network ContinuumEducation, 2006. 160 p. 